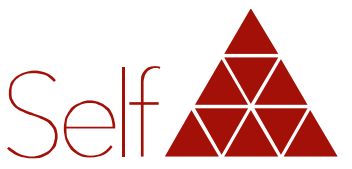

Revista do Instituto Junguiano de Săo Paulo

\title{
Realidade física e a experiência de ser e existir
}

\section{Ricardo Pires de Souza}

São Paulo, SP, Brasil.

\section{Resumo}

A realidade física nos é inacessível e não sabemos o que somos ou o que é a realidade. A psique - a experiência psicológica individual subjetiva, parte consciente e parte profundamente inconsciente - é a única experiência de ser e existir e a única realidade a que temos acesso. A origem da imagem de Deus está na busca de contenção para a perplexidade e para o medo diante da ideia da morte, do desconhecido e da não-existência, e na busca de significado para a experiência psíquica percebida como realidade única. $A$ diversidade de expressões das imagens de Deus - sejam declaradamente religiosas, sejam em suas formulações racionais e matemáticas - é função da cultura e assume forma narrativa psicologicamente verdadeira. Descrever a realidade experimentada é o que nos é possível.

\section{Descritores}

física, vida, consciência, inconsciente, individuação, self, realidade.

Conflito de interesses:

O autor declara não haver nenhum interesse profissional ou pessoal que possa gerar conflito de interesses em relação a este manuscrito.
Recebido: 20 abr 2016; $1^{\text {a }}$ revisão: 17 mai 2016; Aprovado: 25 jul 2016; Aprovado para publicação: 26 set 2016 . 


\title{
Physical reality and the experience of being and existing
}

\begin{abstract}
Physical reality is inaccessible to us and we do not know what we are or what reality is. The psyche - the subjective individual psychological experience, composed by a conscious part and by a deeply unconscious part - is the unique experience of being and existing and the only reality we have access to. The origin of the God image is in searching for restraint of the perplexity and of the fear of death, of unknown and of non-existence, and in searching for meaning to the psychic experience perceived as the only reality. The diversity of expressions of God images - either avowedly religious or rational and mathematical formulations - is a function of the culture and takes a psychologically true narrative form. Describing the experienced reality is what we can do.
\end{abstract}

\section{Descriptors}

physics, life, conscience, unconscious, individuation, self, reality.

\section{Realidad física y la experiencia de ser y existir}

\section{Resumen}

La realidad física nos es inaccesible y no sabemos lo que somos o lo que la realidad es. La psique - la experiencia psicológica individual subjetiva, parte consciente y parte profundamente inconsciente - es la experiencia única de ser y de existir y la única realidad a la que tenemos acceso. El origen de la imagen de Dios está en la búsqueda de contención para la perplejidad y para el miedo ante la idea de la muerte, ante lo desconocido y ante la no existencia, y en la búsqueda de sentido para la experiencia psíquica percibida como realidad única. La diversidad de las expresiones de las imágenes de Dios - sean abiertamente religiosas, o en sus formulaciones racionales y matemáticas - es una función de la cultura y asume forma narrativa psicológicamente verdadera. Describir la realidad experimentada es lo que nos es posible.

\section{Descriptores}

física, vida, conciencia, inconciente, individuación, self, realidad. 


\section{Introdução}

Os últimos 30 anos da civilização têm sido muito impactantes. A revolução da informação teve início no final da década de 1970 com o desenvolvimento dos computadores pessoais e explodiu no final dos anos 1980 com o surgimento da internet, lado a lado com profundos avanços científicos e tecnológicos. Desde então, a sociedade humana vem sofrendo grandes mudanças no comércio, finanças, instituições, política, cultura, arte, educação, relações sociais, demografia, ecologia, religião e na concepção do indivíduo humano. A internet e a tecnologia da informação permitiram a democratização do conhecimento e mudaram o mundo.

A linguagem humana é única: somos capazes de trocar e acumular informações com eficiência superlativa, o que provavelmente nos deu uma vantagem sobre nossos primos evolutivos mais próximos, os extintos Neandertais. Há cerca de seis mil anos, inventamos a linguagem escrita em pelo menos seis lugares independentes: Suméria, Egito, Vale do Indo, China, Creta e Mesoamérica. No século XV, Gutenberg inventou os tipos móveis e iniciou a revolução da imprensa. Todos esses passos nos levaram à criação da World Wide Web, na qual a informação se tornou o fundamento da civilização.

Avanços surpreendentes na física e na cosmologia vêm sendo obtidos desde o fim do século XIX. Em 1900, Max Planck descreveu a base da mecânica quântica. Em 1905, Albert Einstein apresentou a teoria da relatividade especial e, 10 anos depois, a teoria da relatividade geral. Em 1929, Edwin Hubble observou que o universo está se expandindo, levando à teoria do big bang. A ciência da computação permitiu o desenvolvimento de máquinas poderosas para a observação dos mundos cósmico e subatômico. Hoje, manipulamos partículas subatômicas, observamos supernovas, controlamos a antimatéria, lidamos com a relatividade do tempo e ouvimos ecos do universo quando ele tinha 380 mil anos de idade. Ampliamos nosso entendimento do mundo e precisamos de um computador e uma conexão com a internet para obter acesso a esse conhecimento.

A revolução biotecnológica decodificou o DNA e criou o Projeto Genoma. Grandes avanços na farmacologia ocorreram e um extraordinário maquinário biomecânico e cibernético criou interfaces homem-máquina. Estes avanços têm nos possibilitado vidas mais longas e saudáveis e acumulado dilemas éticos. A bioética foi criada para lidar com estes dilemas.

A política tem levado à globalização da democracia e, embora ainda existam muitos regimes totalitários, a maioria das sociedades está ciente de que apenas com o fortalecimento dos princípios democráticos e a racionalização dos recursos da Terra poderemos sobreviver a nós mesmos.

A população humana atual é de cerca de sete bilhões de pessoas, cada uma delas única. $O$ princípio da dignidade humana é uma forma de declaração moral, intrínseca às sociedades democráticas, na qual a vida humana é um fim em si mesma. 
Kant (1785/2013):

No reino dos fins tudo tem ou preço ou dignidade. Quando uma coisa tem preço, pode ser substituída por qualquer outra que the seja equivalente; o que, por outro lado, está acima de todo o preço, e, portanto, não permite equivalente, possui dignidade. (Section 2, position 744)

A civilização é uma forma única de relacionamento. Sua definição se baseia em conceitos antropológicos e históricos: a transição do modelo caçadorcoletor para assentamentos fixos, a domesticação de plantas e animais, a fundação das cidades e a invenção da linguagem escrita. Embora, ao longo da história, a vida humana tenha sido pouco valorizada, ela vem se transformando em valor supremo com o processo civilizatório que é, em si, um caminho para a humanização: o código de Hamurabi, a proscrição da escravidão, a condenação do racismo na Declaração Universal dos Direitos Humanos, as garantias de liberdade de expressão nos regimes democráticos, o estabelecimento dos direitos das crianças, das mulheres e das minorias, e a percepção crescente de que a pobreza precisa ser erradicada são exemplos dessa tendência.

Jung definiu a psicologia como uma disciplina cultural, estabelecendo não ser possível analisar um ser humano sem levar em consideração seu ambiente cultural e social (Zoja, 2005). Essa abordagem é próxima do conceito bioético de autonomia, no qual beneficência, não maleficência e justiça dependem daquilo que cada pessoa compreende como aceitável dentro de seu contexto cultural. Assim, diferenças de base histórica, cultural, étnica e religiosa devem ser consideradas na abordagem da pessoa humana.

Esses são os principais temas da nossa era. Mas não podemos esquecer de que falamos de um período de tempo de 30 anos diante de seis mil anos de civilização, 200 mil anos de existência da nossa espécie, seis milhões de anos de existência dos hominídeos, 65 milhões de anos de prosperidade dos mamíferos na Terra, 600 milhões de anos desde o surgimento dos seres grandes na Explosão do Cambriano, 3,5 bilhões de anos de vida na Terra, 4,5 bilhões de anos de existência da própria Terra, cinco bilhões de anos desde a formação do Sistema Solar, 11 bilhões de anos desde o início da formação da Via Láctea, 13,7 bilhões de anos de existência do universo.

\section{0 método científico}

Elaboramos perguntas acerca da realidade: o que é o universo? $\bigcirc$ que é a vida? $\bigcirc$ que é a psique? $\bigcirc$ universo teve um início ou ele é eterno? $\bigcirc$ que haveria além de um universo finito? $\bigcirc$ que é a energia? $\bigcirc$ que é a matéria? $\bigcirc$ que é a antimatéria? $\bigcirc$ que é o espaço-tempo? $\bigcirc$ que é a gravidade? Qual a diferença entre matéria não viva e vida? Como a matéria não viva se tornou viva? Qual é o caminho que leva do genoma à expressão fenotípica? 
Como neurônios, transmissores químicos e sinais elétricos atuam como base da psique? $\bigcirc$ que é a consciência? $\bigcirc$ que é o inconsciente?

Não conseguimos responder a nenhuma destas perguntas. Cientificamente falando, não sabemos o que somos ou o que é a realidade. $O$ senso comum costuma se referir a esses desconhecimentos como mistérios, enigmas ou lacunas no conhecimento: não são lacunas, são fundamentos. Todo conhecimento se baseia em um desconhecimento fundamental.

De que maneira podemos então tentar responder às questões acerca da realidade?

Começamos a fazê-lo por meio do pensamento simbólico e por narrativas orais, plásticas e gráficas, no chamado big bang da mente. Os primeiros registros de comunicação simbólica datam do período Paleolítico Superior, principalmente por meio do surgimento de esculturas e da arte parietal, mas também com a crescente sofisticação de ritos funerários, ornamentos e armas (Balter, 2009). O pensamento simbólico não é exclusivo do Homo sapiens, mas é identificado no Homo neanderthalensis (Zilhão et al., 2010), e é, enfim, uma característica primata (Tomasello, 2000).

pensamento racional passou a se impor com o surgimento da filosofia grega no século VI a.C. Mas Hawking e Mlodinow (2010, p. 5) afirmam que a filosofia morreu porque não acompanhou os desenvolvimentos da ciência moderna. A ciência é empírica, matemática e baseada em evidências. Seu maior objetivo é predizer eventos por meio da identificação de padrões repetitivos. A ciência não é apenas causal: a explicação etiológica é a confirmação de qualquer predição, mas não é imprescindível.

Cientistas tendem a selecionar problemas passíveis de serem tratados matematicamente, excluindo fenômenos para os quais predições matemáticas não são possíveis. $\bigcirc$ valor preditivo de qualquer teste depende da constância das relações subjacentes entre variáveis, o que não ocorre com sistemas físicos que desenvolvem caos (Lívio, 2011) ou sentimentos. Enquanto ferramenta para avaliar a realidade, a matemática é limitada, como demonstra o teorema da incompletude de Gödel que afirma que qualquer sistema completo é necessariamente inconsistente e que, para ser consistente, um sistema precisa ser incompleto, dependendo de axiomas externos que não podem ser provados.

A abordagem biológica depende de ferramentas estatísticas e sua preditibilidade é enviesada por fragilidades das amostras e dos desenhos de pesquisa. E embora a medicina baseada em evidências tenha sido desenvolvida em uma tentativa de reduzir esses vieses, a abordagem de questões biológicas se refere a partes da economia humana e apenas a algumas partes por vez, não alcançando a totalidade de uma pessoa singular.

O fenômeno psicológico torna ainda mais difícil a aplicação do paradigma científico. Embora exista um arcabouço empírico, neurocientífico, cognitivo e comportamental, a análise final da experiência psicológica está sob 
abordagem fenomenológica e perspectiva dinâmica. A singularidade da psique individual não é compreensível pelo método científico porque a amostra é $n=1$. Isso não significa que o modelo observação-teoriaobservação não tenha valor: conteúdos psicológicos são fenômenos e, portanto, passíveis de observação a despeito das dificuldades que tal observação represente.

Outro viés metodológico fundamental é que o observador é um agente interferente no fenômeno observado: isso é crítico em experimentos físicos, definidor na pesquisa biológica e totalmente inseparável da abordagem fenomenológica do evento psicológico; há sempre um "como" o fenômeno é visto (Colman, 2009). Na experiência psicológica, observador, observação e objeto de observação são a mesma coisa. Teorias são sugestões de como as coisas podem ser consideradas e são métodos auxiliares de produção de conhecimento; toda vez que se tornam explicações definitivas causam exageros, por isso precisamos de muitos pontos de vista para proporcionar uma imagem da realidade (Jung, 1985a, CW 16: 198). A verdade científica de hoje, amanhã, será erro, e há sempre uma fronteira em transição entre o conhecido e o desconhecido, talvez a única coisa realmente previsível acerca do fenômeno humano.

\section{0 universo}

Este universo - que é o único que conhecemos - teve um início e isso ocorreu há 13,7 bilhões de anos a partir de uma imensa expansão de matéria. Desde então, ele continua a se expandir e esfriar.

Em $10^{-35}$ segundo após o big bang havia uma sopa quente e informe de quarks, léptons e energia, criada pela inflação cósmica. Em $10^{-11}$ segundo a matéria superou a antimatéria. Em $10^{-5}$ segundo ocorreu a nucleossíntese com quarks formando prótons e nêutrons. Em cinco minutos apareceram os núcleos de hélio, lítio e hidrogênio pesado. Aos 380 mil anos a formação dos átomos liberou a radiação cósmica de fundo em micro-ondas e o universo se iluminou. Entre 100 e 300 milhões de anos a gravidade continuou a aumentar as diferenças de densidade sobre o gás que preenchia o espaço e pequenos agrupamentos de matéria formaram as primeiras estrelas. Da explosão e da destruição destas estrelas surgiram os elementos mais pesados da tabela periódica e novas estrelas. De três bilhões de anos em diante os aglomerados de galáxias começaram a se formar com picos de formações de galáxias e estrelas. Existem cerca de 100 bilhões de galáxias no universo visível, cada uma contendo 100 bilhões de estrelas e incontáveis planetas e luas (Turner, 2009).

O universo está se expandindo. Hubble demonstrou que as galáxias estão se afastando e que as galáxias mais distantes se afastam mais rapidamente. A divergência observável do universo permite que possamos percorrer o caminho contrário e a consequência é a teoria do big bang. 
Energia, matéria, espaço-tempo e gravidade tiveram início simultaneamente de um estado infinitamente pequeno, denso e quente: uma singularidade (Steiner, 2006). Uma singularidade é algo que não está sujeito às leis físicas e matemáticas, apresentando comportamento indefinido e inexplicável devido aos seus valores infinitos. Os precursores de tudo o que existe estavam esmagados em um ponto matemático de dimensão zero e temos evidências do que ocorreu nos instantes após o big bang, mas nada sabemos acerca do momento no qual o tempo era igual a zero.

A teoria do big bang cria o problema acerca do que haveria antes do início do universo porque não deveria haver nada antes dele: é impossível incluir o conceito de "além de um universo finito" no modelo científico.

Muitos cientistas rejeitam a ideia de singularidade e teorias foram desenvolvidas para explicar o universo sem ela, quase todas baseadas na mecânica quântica; o big bang sendo concebido como momento transicional entre estados anterior e posterior de um universo eterno (Veneziano, 2012). De acordo com a teoria do universo cíclico, houve uma implosão extrema que alcançou um ponto de densidade máxima antes da expansão (Bojowald, 2008). A teoria do multiverso traz a hipótese de que o nosso universo pode ser um, dentre incontáveis universos desconexos (Ellis, $2011)$.

O universo é composto por três elementos básicos: partículas com massa (férmions), partículas sem massa (bósons) e espaços vazios. Partículas com massa constituem uma parte mínima de cada átomo. As chamamos de matéria. Partículas sem massa são responsáveis pela interação das partículas com massa. As chamamos de energia. A energia se transforma em matéria por meio do processo de aquisição de massa condicionado pelo bóson e pelo campo de Higgs (Riordan, Tonelli \& Wu, 2012).

- modelo padrão de partículas descreve as partículas e as forças fundamentais que constituem matéria e energia (Moreira, 2009) e prediz duas classes de partículas elementares indivisíveis sem nenhuma estrutura interna: léptons (elétrons, por exemplo) e quarks, juntamente com suas antipartículas correspondentes. Estas partículas são os blocos de construção de tudo. Após isso, existem os hádrons, partículas complexas tais como prótons e nêutrons, com estrutura interna composta por quarks e antiquarks.

As duas principais teorias físicas modernas são a teoria da relatividade geral e a mecânica quântica, e elas respectivamente explicam os universos cósmico e subatômico muito bem, mas não são compatíveis uma com a outra: a mais importante questão na física é a busca por uma teoria física unificada (Seife, 2005), chamada de teoria de tudo.

Matéria e energia são equivalentes. Tanto matéria quanto energia podem se comportar como onda ou partícula e, de acordo com o princípio da incerteza de Heinsenberg, é impossível observar simultaneamente a posição e a velocidade de uma partícula ou sua atividade corpuscular e ondulatória. 
Existem quatro interações fundamentais mediadas por partículas sem massa: o eletromagnetismo, responsável por todas as formas de luz e mediada por fótons; a força nuclear fraca, responsável pelo decaimento radioativo, mediada pelos bósons $\mathrm{W}$ e Z; a força nuclear forte, responsável pela fixação dos nêutrons e prótons dentro do núcleo atômico, mediada por glúons; e a gravidade, mediada por grávitons.

A velocidade da luz é a constante mais importante do universo e nada pode se mover mais rápido do que $299.792 .458 \mathrm{~m} / \mathrm{segundos}$. Mas sabemos hoje que a expansão inicial do universo - chamada inflação cósmica - precisou ocorrer a uma velocidade superior à da velocidade da luz e, desse modo, essa constante é válida apenas dentro do universo.

A antimatéria foi criada juntamente com a matéria nos primeiros momentos após o big bang e, inicialmente, havia quase a mesma quantidade de matéria e antimatéria. Como suas partículas apresentam cargas opostas, elas se aniquilam quando se encontram. No nível subatômico, sob altas energias, há simetria de pares de partículas de matéria e antimatéria, mas isso não ocorre no nível macroscópico, onde a antimatéria existe apenas em raios cósmicos e algumas formas de decaimento radioativo. Nosso universo é assimétrico e dominado pela matéria.

Universo como visto hoje poderia não existir, porque tudo teria sido consumido, se não fosse um mínimo e inexplicável excesso de matéria sobre a antimatéria, cerca de um quark a cada bilhão de pares de quarks/antiquarks, e não sabemos a razão deste excesso. Porém, hoje, conseguimos manipular a antimatéria a nosso favor: a tomografia por emissão de pósitrons (que são antielétrons) é uma das mais importantes aquisições recentes no combate ao câncer (Beyer et al., 2000).

A relatividade geral afirma que o espaço e o tempo são inseparáveis, constituindo um continuum espaço-tempo quadridimensional. $\bigcirc$ tempo absoluto, separado do espaço, não existe. $\bigcirc$ espaço-tempo não é fixo: está em permanente mudança; é relativo e faz curvas. Ele se lentifica quanto mais um observador estiver próximo da velocidade da luz, dependendo da força dos campos gravitacionais. Apenas uma partícula sem massa pode viajar a velocidade da luz e assim ela não experimenta a passagem do tempo. A lentificação do tempo e o fenômeno da curvatura do espaço são rotineiramente calculados para obter resultados precisos nos nossos equipamentos de GPS.

As leis físicas são as mesmas para todos os observadores independentemente de seus sistemas de referência. Pode-se escolher qualquer sistema de coordenadas e um eixo para mapear o espaço-tempo, desde que diferentes observadores em diferentes movimentos tenham eixos do tempo em diferentes direções. Cada ponto no espaço-tempo é definido por si e não por meio de sua localização, já que nenhum sistema de coordenadas é especial. Um observador parado irá experimentar a direção temporal. Um observador em movimento irá experimentar um misto de espaço e tempo. 
A questão do tempo é um dos principais obstáculos à unificação das teorias da relatividade geral e da física quântica porque as propriedades do tempo requeridas pelo estado quântico (a descrição completa de um objeto) são antagônicas ao tempo não absoluto de Einstein: na mecânica quântica, o épico do universo ocorre ao longo do tempo e a relatividade geral permite a ideia de um universo atemporal.

Outras teorias buscam por uma explicação quântica. A principal versão da teoria das cordas prediz 10 dimensões (Baez \& Huerta, 2011). A teoria-M (que tenta conciliar as várias teorias das cordas) prediz 10 dimensões espaciais mais o tempo. Alguns cientistas especulam sobre a possibilidade de mais de uma dimensão temporal e mesmo de dimensões nem espaciais nem temporais. A teoria do loop quântico fala de átomos de espaço-tempo, contrariamente à ideia de espaço-tempo contínuo.

Mas, se este universo é finito na direção do passado, porque deveria ser diferente na direção do futuro? $\bigcirc$ fim poderá estar relacionado à dispersão do universo ou a sua contração e colapso (Musser, 2010).

A gravidade foi definida por Isaac Newton como o fenômeno natural por meio do qual corpos físicos mutuamente se atraem. A relação orbital dos corpos cósmicos; a coalescência da matéria que continua a formar estrelas, planetas e galáxias; o peso e o cair das coisas; o escoar da água são todos eventos baseados na mais fraca e mais universal das quatro forças fundamentais da natureza. Tudo o que existe está sob efeito gravitacional e simultaneamente produz gravidade (Novello, 2012). Cada um de nós produz gravidade. A gravidade coloca tudo o que existe em relação com tudo o que existe.

De acordo com a teoria da relatividade geral, a gravidade é uma consequência da curvatura do espaço-tempo em sua relação com a matéria, governando o movimento inercial das coisas. Mas a relatividade não pode descrever a estrutura quântica do espaço-tempo. Em distâncias menores do que o comprimento de Planck $\left(1,6 \times 10^{-35} \mathrm{~m}\right)$, o comportamento das partículas escapa tanto da relatividade geral quanto da mecânica quântica (Smolin, 2004).

Toda a matéria que conhecemos - chamada matéria bariônica e correspondendo à soma de todos os prótons e nêutrons conhecidos representa $5 \%$ de toda a matéria do universo e não é suficiente para explicar a densidade e consequente estabilidade gravitacional do universo: é necessária a existência de uma matéria desconhecida responsável por isso: ela é chamada matéria escura. A matéria escura supostamente não é formada por átomos e não emite ou absorve a luz, sendo invisível. Não sabemos o que é a matéria escura (Feng \& Trodden, 2010) ou mesmo se ela existe.

Além disso, é necessário ainda existir uma força antigravitacional desconhecida chamada energia escura, responsável pela aceleração da expansão do universo nos últimos cinco bilhões de anos (Riess \& Turner, 
2004). Esta força é responsável, juntamente com a matéria escura, pela maior parte da densidade do universo, mas não sabemos o que é a energia escura ou se ela de fato existe (Clifton \& Pereira, 2009).

\section{A vida}

De acordo com a teoria da sopa primordial, sob as condições extremas da existência inicial da Terra, a associação de água líquida, atividade vulcânica intensa, descargas elétricas atmosféricas violentas e impactos de corpos cósmicos provocou reações químicas que transformaram átomos e moléculas básicas em grupamentos moleculares mais complexos (Ehrenfreund et al., 2002). Mas não sabemos qual era a composição prebiótica da Terra ou qual era sua atmosfera. Supomos que a partir do carbono, hidrogênio, oxigênio, nitrogênio e enxofre surgiram glicoproteínas, fosfolipídeos, aminoácidos e outras macromoléculas que finalmente produziram os ácidos ribonucleico (RNA, do inglês ribonucleic acid) e desoxirribonucleico (DNA, do inglês deoxyribonucleic acid) (Orgel, 2004).

O DNA é a base estrutural da vida e faz com que todos os seres vivos compartilhem a mesma herança. É um complexo macromolecular orgânico em forma de dupla hélice, descrito por James Watson e Francis Crick em 1953, e contém as determinações genéticas para o desenvolvimento e funcionamento dos seres vivos, por meio da produção de proteínas. É responsável pela transmissão das características hereditárias.

O DNA é a molécula mais complexa do universo. Parte dele contém informação genética, constituindo os genes; outras partes agem nos processos regulatórios da informação genética ou possuem função estrutural. No entanto, o DNA sozinho não explica a vida.

Não sabemos como o RNA e o DNA se formaram porque não existe registro fóssil e os processos nunca foram reproduzidos, seja por meio de observação da natureza seja em laboratório. A teoria corrente afirma que de algum modo moléculas complexas de matéria não viva vieram a se tornar seres vivos (Zimmer, 2009), mas essa ideia nunca foi comprovada. Recentemente, Craig Venter e seu time criaram uma forma de vida sintética introduzindo um genoma sintético dentro de uma bactéria previamente esvaziada de seu DNA: a bactéria começou a se replicar e a produzir novas proteínas (Pennisi, 2010). Porém, isto não é criar vida da matéria não viva.

A hipótese de que a vida tenha chegado à Terra em meteoritos (panspermia) é especulativa e de todo modo não resolve a questão sobre como a vida se iniciou. A Terra é o único lugar no universo observável onde a vida é identificada.

Alguns pensadores utilizam o conceito biológico de "emergência" para explicar o surgimento da vida, significando um sistema que excede predições que possam ser feitas a partir da análise de seus componentes e forças constituintes (Balazs \& Epstein, 2009). Esse conceito se sobrepõe ao de 
"sistema complexo" utilizado com o mesmo significado em física, meteorologia, economia etc.

Assumimos, por definição, que a vida começa com uma célula. Esta possui material genético, destinado a sua perpetuação, metabolismo complexo e uma membrana semipermeável que a separa do mundo externo. De acordo com essa definição, vírus e príons não são seres vivos. Mas a definição de vida é objeto de controvérsias.

Um vírus é um complexo encapsulado de DNA. Embora apresente genoma, não possui ribossomos e outras organelas responsáveis pela produção de enzimas e de energia necessárias para o metabolismo complexo; não é capaz de crescer ou de se dividir; e depende de uma célula para se reproduzir e para obter proteínas e energia: um vírus é um parasita intracelular exclusivo, e fora de uma célula é inerte (Lwoff, 1954).

Um príon é uma proteína que não é composta por ácidos nucleicos e não possui cápsula. Ainda assim, é um agente infectante em células de mamíferos, obrigando-as a produzirem cópias de si (Prusiner, 1984). As infecções por príons causam a doença da "vaca louca" no gado e a doença de Creutzfeldt-Jakob em humanos.

Em 1859, Charles Darwin demonstrou o processo de evolução das espécies por meio da seleção natural. A evolução da vida é compulsória (Benton, 2009). A genética prova isso: embora existam muitas outras fontes de evidências para reafirmar a teoria da evolução (Pigliucci, 2009), é pouco provável hoje um estudo científico sem análise genômica se houver material genético disponível. Esforços para o sequenciamento genético de todos os seres vivos estão no topo das buscas científicas (Pennisi, 2009).

A teoria da evolução afirma que todas as espécies evolvem para outras espécies ou desaparecem em um processo aberto e ramificado; que a evolução das espécies é uma função exclusiva de mutações genéticas e sua relação com o meio ambiente; que as espécies derivam de ancestrais comuns na árvore da vida; que toda espécie é caracterizada pela diversidade populacional; e, finalmente, introduz a morte como uma força criativa da natureza (Bowler, 2009). No entanto, ela lida com a evolução dos seres vivos a partir de outros seres vivos e não explica a origem da vida, embora aponte para ela de forma convergente, de maneira análoga à que leva à teoria do big bang a partir da expansão do universo.

A interpretação mecanicista da teoria da evolução afirma que não somos o ápice do processo evolucionário, já que muitas espécies existiam antes do nosso aparecimento e, muito provavelmente, várias irão persistir se desaparecermos. Além disso, apesar da nossa dominância momentânea (e questionável) sobre o meio ambiente, outras espécies podem representar exemplos mais significativos de sucesso evolutivo. Nossas capacidades são adaptações fenotípicas de aparência aleatória, sem nenhuma intencionalidade, finalidade ou valor particular no universo e na evolução da vida. Qualquer interpretação a posteriori que suponha que o passado age 
para produzir nosso presente específico e qualquer noção antrópica de que as leis físicas e as constantes fundamentais do universo possam ser um arranjo calculado cuja meta seja a existência da humanidade precisam ser rejeitadas (Dawkins, 2004, p. 2). $\bigcirc$ acaso dirige a evolução.

Mas a vida modifica o meio ambiente. Vernadsky (1998) aponta que a biosfera age como força geológica. Ele adotou o termo "noosfera" para a camada pensante da matéria, indicando que a humanidade também se comporta como fenômeno geológico. Margulis (2013) afirma que há intencionalidade na vida interferindo em sua evolução, resultado de relacionamentos simbióticos entre seres vivos. Maturana e Varela (1987) afirmam que a vida é autopoiética: a vida cria a si mesma de forma autônoma e sua única meta é criar a si mesma. De acordo com a teoria Gaia de Lovelock (1995), a Terra é um organismo vivo: a biosfera está em sinergia com os elementos físicos e é caracterizada pela intencionalidade e pela capacidade regulatória para manter condições favoráveis para seus próprios componentes.

A questão sobre se a vida apresenta intencionalidade ou é simples mecanismo é crucial e está relacionada ao fenômeno do livre arbítrio. Margulis e Sagan (2002, p. 22) estabelecem separação estrita entre vida e morte e criticam tanto o animismo quanto o mecanicismo: por um lado, a vitalização da matéria ignora a diferença entre o que vive, o que está morto e o que nunca esteve vivo; e, por outro, como mecanismos reagem e não agem, o mecanicismo nega a autonomia e a intencionalidade da vida, assim como o livre arbítrio humano, inferindo a ideia de um projetista pessoal e levando a uma perspectiva profundamente metafísica.

Fenótipo é definido como o todo complexo das características de um ser vivo - tais como sua morfologia, fisiologia, metabolismo, desenvolvimento e comportamento -, resultante da expressão genética sob a influência de fatores ambientais. Deve haver um caminho que leva do mapa genômico à totalidade das características fenotípicas por meio do DNA codificador e não codificador, do RNA, de proteínas regulatórias, de alterações genômicas químicas e estruturais e de processos epigenéticos (Goldman, 2009). Algumas vezes conseguimos trilhar este caminho para traços específicos, mas isso não é possível para a maioria dos eventos biológicos. Não sabemos como meros 25 mil genes produzem centenas de milhares de proteínas diferentes (Pennisi, 2005) e, enfim, nós.

\section{A psique}

Nossos ancestrais ficaram em pé. Parece que estar com a cabeça pouco mais do que um metro acima do solo das savanas representou redução de alguns graus de temperatura sobre ela. Eles passaram a seguir os grandes felinos e a se alimentar das carcaças após os demais carnívoros não conseguirem comer mais nada delas: com o auxílio de instrumentos de pedra, eles passaram a obter a porção mais calórica, a medula óssea. Eles passaram a assar a carne, gastando menos energia no processo digestivo e 
oferecendo um excesso de suprimento sanguíneo ao cérebro. Esses e outros eventos facilitaram o crescimento cerebral.

Nosso cérebro funciona por meio de substâncias neuroquímicas e impulsos elétricos entre suas principais células, os neurônios. A fisiologia eletroquímica do cérebro é a base estrutural da psique. A neurociência permite a identificação de áreas cerebrais como sítios de funções psíquicas superiores, tais como pensamentos, sentimentos, memória etc.; demostra a plasticidade cerebral na recuperação de funções por meio de caminhos neurais alternativos após a desativação de áreas específicas do cérebro; e até eventualmente identifica anormalidades em circuitos neurais relacionados a doenças mentais (Akil et al., 2010). Neurocientistas estão capturando impulsos cerebrais elétricos e desenvolvendo interfaces cérebro-máquina capazes de mover estruturas cibernéticas, abrindo um campo inimaginável de possibilidades (Nicolelis, 2011). Ainda assim, não sabemos o caminho que vai de algumas poucas substâncias intermediando impulsos elétricos entre neurônios à complexidade da experiência psíquica (Miller, 2005), e simplesmente conectar o órgão à função pode levar aos mesmos erros da frenologia e da craniologia.

Podemos entender a vida e a psique como unidade biopsíquica. Mesmo a mais básica forma de vida, um organismo unicelular, tem alguma forma de psique já que procura por comida e abrigo e possui o instinto de se perpetuar, de algum modo fazendo escolhas.

Atualmente, o transumanismo reafirma a ideia mecanicista de que consciência é um epifenômeno da biologia e, como todos os seres vivos são formas transicionais e incompletas, não há uma definição ontologicamente válida de ser humano, permitindo uma superação do estado humano atual. Devemos tentar prevenir, controlar ou curar doenças físicas e mentais por meio do mapeamento genético, engenharia cibernética, nanotecnologia, farmacologia, manipulação de células tronco etc., mas podemos melhorar de forma ilimitada a natureza humana, por exemplo, mudando características indesejadas da personalidade e apagando memórias dolorosas (Han et al., 2009), e permitindo que os seres humanos vivam talvez por 150 ou 200 anos como jovens (Couzin, 2005). O ápice do ser transumano seria, por meio de interfaces mente-máquina, manter a consciência em um maquinário de durabilidade perpétua.

Se considerarmos a aceleração exponencial da produção de conhecimento resultante da revolução da informação durante os últimos 30 anos, pode não ser tão improvável a ocorrência de uma "singularidade tecnológica", hipótese que prediz para muito breve um avanço tecnológico incalculável, acontecendo em um período de tempo muito curto, com consequências imprevisíveis: talvez um cenário próximo ao Admirável Mundo Novo de Aldous Huxley, no qual introversão, solidão, sofrimento e envelhecimento seriam abolidos.

A consciência é a instância psíquica caracterizada pelo pensamento racional e dirigido (Jung, 1976a, CW 5: 11), conduzindo à adaptação, refletindo 
sobre o mundo, apresentando questionamentos metafísicos, criando códigos morais, produzindo conhecimento e desenvolvendo ciência. É um evento recente na evolução humana, podendo-se considerá-lo de forma sobreposta à história da civilização. Graças à consciência humana, avanços científicos e tecnológicos têm propiciado melhorias em recursos, alimentação, proteção contra doenças, qualidade de vida e longevidade; nosso conhecimento tem crescido exponencialmente e há um aumento na tolerância e na justiça, com melhores leis e códigos derivados de princípios éticos baseados nos direitos e na dignidade da pessoa humana. Infelizmente, esses avanços ainda não representam universalidade da justiça. Também, graças à ciência, nos tornamos predadores de nós mesmos mais competentes. Isso resulta em tribalismo, terrorismo, racismo, guerras, distribuição autocrática dos recursos do planeta, destruição da biosfera, corrupção e injustiça social: o próprio desenvolvimento da consciência causa dissociação psíquica, sofrimento e doença.

Os modos consciente e inconsciente de identificar, organizar e responder a questão "o que é a realidade?" são diferentes: o pensamento simbólico responde a partir de uma perspectiva coletiva, intuitiva, emocional, analógica e imagética; a consciência responde por meio do "eu" (ou "ego") de uma forma dominantemente racional. A consciência assume a posição de observadora e controladora do mundo por excelência. Nada pode ser consciente sem um ego como ponto de referência, assim como tudo o que não se relaciona com o "eu" é inconsciente: podemos definir a consciência como a relação entre os fatos psicológicos e o "eu". E a consciência nos diferencia do restante do mundo. Mas, ainda assim, embora a consciência seja equivalente ao próprio surgimento da psique, da vida e do universo - já que todos esses eventos parecem representar fatos novos na existência - ela não corresponde à totalidade da psique (Jung, 1979, CW 9/2: 9). Chamamos "inconsciente" a parte situada além da consciência. No entanto, a consciência tem a função da vida adaptativa e busca controlar o mundo ao redor e dentro de si: é da natureza intrínseca da consciência ver a si mesma como ápice e consequentemente desprezar a condição de criatura ou representante. Orgulho e egocentrismo da cultura e da civilização são expressões desse processo, assim como individualismo exagerado. A consciência coloca a psique inconsciente em um nível subsidiário, atribuindo-Ihe papel reativo e passivo e, eventualmente, conecta a psique com sentimentos aversivos.

A psique - consciente e inconsciente - apresenta autonomia e intencionalidade e suas partes não podem existir normalmente uma sem a outra. Os modos de operação de ambas são baseados em determinantes preexistentes no inconsciente coletivo: os arquétipos. A consciência nasce de e se assenta na psique inconsciente. $\bigcirc$ próprio desenvolvimento da consciência é arquetípico e cada um de nós possui um projeto inato para formá-la. Assim, não somos somente a parte consciente da nossa psique, e a consciência não é nem mesmo seu centro, mas uma parte funcional que se torna disfuncional quando tenta ver a si mesma como exclusiva. 
A teoria do inconsciente de Sigmund Freud revolucionou a psicologia e a civilização: ele demonstrou o quão profundamente o inconsciente interfere e eventualmente domina a atividade consciente. Mas, sob a perspectiva de Freud, o inconsciente é produzido a partir da consciência. De fato, existem conteúdos inconscientes que já foram outrora conscientes, constituindo o que Jung chama de "inconsciente pessoal". Porém, há uma evolução filogenética, comportamental e histórica da psique gerando conteúdos que nunca estiveram acessíveis à consciência individual: a esse inconsciente profundo Jung chamou de "coletivo", porque ele se relaciona com a história impessoal de cada um dos seres humanos. $O$ inconsciente coletivo influencia e dirige profundamente nossas vidas do zigoto à morte.

Somos parentes de microrganismos que provavelmente apareceram na escuridão do oceano profundo e mais tarde passaram a viver da energia do Sol. Compartilhamos com vermes chatos de 600 milhões de anos uma morfologia bilateral e o primeiro sistema nervoso: os olhos; com os peixes, compartilhamos a coluna vertebral; com os primeiros anfíbios, a experiência da vida em terra; com os mamíferos, a experiência de sugar o leite de nossas mães. Compartilhamos com Ardi (Ardipithecus ramidus) e Lucy (Australopithecus afarensis) uma perspectiva particular derivada do bipedalismo, incluindo nossas frequentes dores nas costas. Todas essas experiências são parte da nossa herança. A teoria do inconsciente coletivo afirma que isso é verdade não apenas biologicamente, mas também psicologicamente (Jung, 1985b, CW 4: 728).

Não somos capazes de mensurar o inconsciente. Embora estudos estejam tentando medir a quantidade de atividade inconsciente, supostamente sempre haverá uma psique inconsciente independente e indefinida no desenvolvimento da consciência. Todo evento psicológico, mesmo o mais racional, possui um componente simbólico inconsciente, derivado de sua natureza desconhecida. E o medo do desconhecido habita o inconsciente.

\section{Imagem de Deus}

fenômeno da imagem de Deus, consideradas todas as suas formas, apresenta alta prevalência em qualquer recorte populacional e de tempo, e é um conteúdo psíquico (ou grupo de conteúdos) responsável por duas funções principais: dar contenção ao medo do desconhecido e servir como valor supremo que oferece significado à experiência psicológica que chamamos de "realidade". É revestido de emoção e de energia psíquica (Jung, 1973, CW 11:3).

Jung identificou no inconsciente profundo um arquétipo impessoal que determina a formação da imagem de Deus (Jung, 1976b, CW 18: 1567): ele toma o Self como sendo simultaneamente o centro e a totalidade da experiência psíquica.

Lidamos com o dilema existência/não-existência como prerrogativa da imagem de Deus, e toda religião possui um mito de criação, se o 
interpretamos como a imagem que dá significado à existência (von Franz, 2003). Ele é responsável por e, simultaneamente, transcende o tempo e a existência, permitindo que imagens do além-tempo e além-morte tenham significado.

O dilema da existência imaterial pode ser observado desde o surgimento dos sepultamentos rituais, passando por todas as mitologias da antiguidade, até chegar às religiões modernas. As construções de 11 mil anos de Göbekli Tepe (atual Turquia) são templos erguidos no período Neolítico Acerâmico, precedendo a produção da cerâmica e o estabelecimento da agricultura e da criação de animais, evidenciando a transformação das sociedades de caçadores-coletores para o modo de vida neolítico, não por razões econômicas e ambientais, mas principalmente sob o impacto da esfera transcendental (Schmidt, 2000).

Podemos encontrar o que provavelmente foi a primeira versão escrita da nossa busca por imortalidade no épico de Gilgamesh mesopotâmico (Gardner \& Maier, 1985). A religião do antigo Egito era sua própria relação com o além-morte (Budge, 1996).

$\mathrm{Na}$ tradição judaico-cristã, Yahweh é a resposta para o dilema existência/não existência, e a criação é o trabalho de um único deus, criador eterno existente desde antes da criação, dando ordem e justificando o mundo: Deus insufla a vida. Alá apresenta a mesma potencia na tradição islâmica.

A tradição védica apresenta uma entidade incognoscível, impessoal e suprema: quando Brahman abre os olhos (um dia de Brahman) a existência começa e quando Brahman os fecha (uma noite de Brahman) a existência deixa de ser. Mais tarde, no Bhagavad Gita, Krishna assume ser o responsável pessoal por Brahman (Wilkins, 1785). Os Upanishads afirmam que o Atman (o verdadeiro "eu") busca pelo encontro com o Brahman impessoal e, ao longo de toda a sequência de vidas, Atman e Brahman são o mesmo, identificando o ser humano com tudo o que vive e tudo o que existe (Tinôco, 1996).

O budismo nega a existência de um criador de tudo (Armstrong, 2000). Ainda assim, o nirvana possui o valor de imagem de Deus tanto quanto a imagem do Buda. Foi a partir de sua experiência acerca do envelhecimento, sofrimento, doença e morte, que Sidarta Gautama iniciou sua jornada para se tornar o Buda, um estado alcançável por todo ser humano (Bancroft, 1997).

A imagem de uma substância original existente no início, no fim e permeando toda a existência aparece com os filósofos pré-socráticos. Embora esse seja o ponto de partida do domínio do pensamento racional, tal ideia era formulada para lidar com a esfera divina (Reale \& Antiseri, 2003 , p. 19). Muitas formas de pensamento religioso e filosófico acreditam que a vida biológica e a psique são separadas, afirmando a existência de uma alma imortal. Sócrates afirmou que o ser humano é sua própria psyché: 
o "eu" consciente caracterizado pela razão, a personalidade intelectual e moral.

A imagem de Deus, no pensamento transumano, é o ser transumano - a criatura mente-máquina - obra do gênio humano. Há também paralelo teleológico entre os conceitos soteriológico e do nirvana e o anseio transumano de sobrepujar o sofrimento, a doença, o envelhecimento e a morte.

Embora as teorias físicas modernas sejam baseadas em poderosas evidências, elas são especulativas. Desse modo, a teoria do big bang, a teoria das cordas, a teoria do loop quântico, a teoria do multiverso, a teoria da sopa primordial, a teoria da panspermia e a perspectiva mecanicista da teoria da evolução, entre outras, são cosmogonias, estruturadas no modo de operação da consciência racional e matemática, mas ainda assim baseadas na força arquetípica do inconsciente profundo, fundamento psíquico de todo ser humano (Jung, 1980, CW 9/1: 125). O confronto entre as várias teorias científicas empíricas e não empíricas, os argumentos filosóficos e os mitos de criação põe em evidência a interdependência e a hostilidade simultâneas entre os pensamentos racional e simbólico; no entanto, parece não haver uma diferença real entre os mitos de criação e as teorias científicas: nenhum deles revela a natureza última da realidade e ambos são desenvolvidos para proporcionar contenção psicológica para o medo do desconhecido, da morte e da não-existência e para oferecer significado à existência.

\section{A realidade}

Somos algo. De acordo com Jung (1986), este "algo" é a psique:

Nada de objetivo sabemos a seu respeito, pois tudo o que dela sabemos é ela própria, a alma é a experiência direta de nosso ser e existir. Ela é para si mesma a experiência única e direta e a "conditio sine qua non" da realidade subjetiva do mundo em geral. Ela cria símbolos cuja base é o arquétipo inconsciente e cuja imagem aparente provém das ideias que o consciente adquiriu. (p. 220-221; 1986, OC V: 344).

A neuropsicologia confirma a ideia de que não vemos o que existe, mas recriamos o mundo em nossas mentes, gerando uma realidade peculiar (Hood, 2013). A realidade física é, desse modo, parte ilusão sensorial, parte imaginação. $\bigcirc$ princípio holográfico faz a hipótese de que o mundo físico pode ser composto por informação, e o universo é uma projeção holográfica (Bekenstein, 2003). Hawking e Mlodinow (2010) desenvolvem a ideia de realismo modelo-dependente, no qual a realidade depende do observador e da eficácia do modelo em descrever o fenômeno. Hoje milhões de pessoas gastam parte de suas vidas em mundos virtuais, existindo como personagens ou avatares na internet (Bainbridge, 2007).

Embora isso obviamente não signifique que o universo não exista, exceto por nós, tudo o que nos alcança - consciente ou inconscientemente - por meio 
do nosso corpo e dos nossos sentidos (incluindo a percepção do nosso próprio corpo), assim como tudo o que ocorre no nosso mundo interno, é exclusivamente experiência psíquica; e tudo o que cada ser humano produz ou expressa é produto da psique. Experimentamos o que somos, a vida e o universo em que existimos; e cada um de nós o faz dentro de si de uma forma que chamamos de "psicológica": um modo interno, subjetivo, individual e incomunicável.

A experiência de ser é incomunicável, pois, toda linguagem, incluindo a matemática, é mera aproximação, nunca a realidade inacessível que cada pessoa experimenta como ser e existir. Assim, há um nível de entendimento no qual não há diferença entre linguagem e mitologia e toda tentativa de comunicar cria uma descrição da realidade: literária, teológica, filosófica ou científica.

\section{Descrições da realidade são histórias contadas}

Sob as leis fundamentais da física, a evolução do universo veio desde uma sopa relativamente homogênea de quarks e outras partículas até a diversidade de galáxias que vemos hoje, e, entre elas, há pelo menos um planeta no qual seres vivos habitam e evoluem, com pelo menos uma espécie que experimenta um estado psicológico por meio do qual cria símbolos e cosmogonias, tecnologia e ciência.

Não sabemos como o universo começou, se o universo é finito ou infinito, o que haveria além de um universo finito, o que é a matéria, a energia, a antimatéria, o espaço-tempo e a gravidade. Não sabemos como a matéria não viva se tornou viva, qual é a diferença entre matéria não viva e a vida e qual o caminho que leva do genoma à expressão fenotípica. Não sabemos como neurônios, substâncias químicas e sinais elétricos atuam como base da psique, o que é a consciência, o que é o inconsciente. Não sabemos o que somos ou o que é a realidade. Cada um de nós experimenta o universo, a vida e a si mesmo por meio de uma existência psíquica individual e essa é a única realidade possível. Enquanto buscamos contenção para o medo do desconhecido, da morte e da não-existência, e significado para essa experiência que somos, inevitavelmente, produzimos imagens de Deus em toda a sua diversidade de expressões, expressões exclusivamente humanas, que resultam invariavelmente em narrativas da realidade.

\section{Referências}

Akil, H., Brenner S., Kandel E., Kendler K. S., King M. C., Scolnick E., ... Zoghbi H. Y. (2010, March 26). The future of psychiatric research: genomes and neural circuits. Science, 327(5973), 1580-1581. doi: 10.1126/science. 1188654

Armstrong, K. (2000). Buddha. London: Phoenix. 
Baez, J. C., \& Huerta, J. (2011). The strangest numbers in string theory. Scientific American, 304(5), 60-65.

Bainbridge, W. S. (2007, July 27). The scientific research potential of virtual worlds. Science, 317(5837), 472-476. doi: 10.1126/science. 1146930

Balazs, A. C., \& Epstein, I. R. (2009 September 25). Emergent or just complex? Science, 325(5948), 1632-1634. doi:

10.1126/science. 1178323

Balter, M. (2009, February 06). On the origin of art and symbolism. Science, 323(5915), 709-711. doi: 10.1126/science.323.5915.709

Bancroft, A. (1997). The Dhammapada. Rockport: Element.

Bekenstein, J. D. (2003). Information in the holographic universe. Scientific American, 289(2), 58-67.

Benton, M. J. (2009). The red queen and the court jester: species diversity and the role of biotic and abiotic factors through time. Science, 323(5915), 728-732. doi: 10.1126/science. 1157719

Beyer, T., Townsend, D. W., Brun, T., Kinahan, P. E., Charron, M., Roddy, R., ... Nutt, R. (2000). A combined PET/CT scanner for clinical oncology. The Journal of Nuclear Medicine, 41 (8), 1369-1379.

Bojowald, M. (2008). Follow the bouncing universe. Scientific American, 229(4), 44-51.

Bowler, P. J. (2009 January 09). Darwin's originality. Science, 323(5911), 223-226. doi: 10.1126/science. 1160332

Budge, E. A. W. (1996). The Book of the Dead. New York: Gramercy Books.

Clifton, T., \& Pereira, P. G. (2009). Does dark energy really exist? Scientific American, 300(4), 48-55.

Colman, W. (2009). Theory as metaphor: clinical knowledge and its communication. Journal of Analytical Psychology, 54(2), 199-215. doi: 10.1111/j.1468-5922.2009.01770.x

Couzin, J. (2005, July 01). How much can human life span be extended? Science, 309(5731), 83. doi: 10.1126/science.309.5731.83

Dawkins, R. (2004). The ancestor's tale: The dawn of evolution. Boston: Houghton Mifflin Company.

Ehrenfreund, P., Irvine, W., Becker, L., Blank, Brucato, J. R., Colangeli, L., ... International Space Science Institute ISSI-Team. (2002). Astrophysical and astrochemical insights into the origin of life. Reports on Progress in Physics, 65, 1427-1487. Recuperado em 25 de abril de 2016, de https://www.researchgate.net/profile/J_Brucato/publication/231078506_A strophysical_and_astrochemical_insights_into_the_origin_of_life/links/0dee c51 dedcfeca120000000.pdf 
Ellis, G. F. R. (201 1). Does the multiverse really exist? Scientific American, 305(2), 38-43.

Feng, J., \& Trodden, M. (2010). Dark worlds. Scientific American, 303(5), 38-47.

Gardner, J., \& Maier, J. (1985). Gilgamesh, translated from the Sîn-LeqiUnninni version. New York: Vintage Books.

Goldman, M. (2009, August 14). Epigenetic determinism. Science, 325(5942), 816. doi: 10.1126/science. 1175293

Han, J., Kushner S. A., Yiu A. P., Hsiang H. L., Buch T., Waisman A., ... Josselyn S. A. (2009). Selective erasure of a fear memory. Science, 323(5920), 1492-1496. doi: 10.1126/science. 1164139.

Hawking, S., \& Mlodinow, L. (2010). The grand design. New York: Bantan Books.

Hood, B. (2013). Recriando a realidade. Scientific American Mente Cérebro, $241,48-51$.

Jung, C. G. (1973). Psychology of religion: West and East. In C. G. Jung, The Collected Words (Vol. 11) [Kindle]. New Jersey: Princeton University Press. Retrieved from Amazon.com

Jung, C. G. (1976a). Symbols of transformation. In C. G. Jung, The Collected Words (Vol. 5) [Kindle]. New Jersey: Princeton University Press. Retrieved from Amazon.com

Jung, C. G. (1976b). The symbolic life. In C. G. Jung, The Collected Words (Vol. 18) [Kindle]. New Jersey: Princeton University Press. Retrieved from Amazon.com

Jung, C. G. (1979). Aion: Researches into the phenomenology of the Self. In C. G. Jung, The Collected Words (Vol. 9/2) [Kindle]. New Jersey: Princeton University Press. Retrieved from Amazon.com

Jung, C. G. (1980). Archetypes and the collective unconscious. In C. G. Jung, The Collected Words (Vol. 9/1) [Kindle]. New Jersey: Princeton University Press. Retrieved from Amazon.com

Jung, C. G. (1985a). Practice of psychotherapy. In C. G. Jung, The Collected Words (Vol. 16) [Kindle]. New Jersey: Princeton University Press. Retrieved from Amazon.com

Jung, C. G. (1985b). Freud and psychoanalysis. In C. G. Jung, The Collected Words (Vol. 4) [Kindle]. New Jersey: Princeton University Press. Retrieved from Amazon.com

Jung, C. G. (1986). Símbolos da Transformação. In C. G. Jung, Obras Completas (Vol. V). Petrópolis: Ed. Vozes.

Kant, I. (1785/2013). Fundamental principles of the metaphysic of morals [Kindle]. Retrieved from Amazon.com 
Lívio, M. (201 1). Why math works. Scientific American, 305(2), 80-83.

Lovelock, J. (1995): Gaia: A new look at life on Earth [Kindle]. Retrieved from Amazon.com

Lwoff, A. (1954). The life cycle of a virus. Scientific American, 190(3), 34-37.

Margulis, L., \& Sagan, D. (2002). O que é vida? Rio de Janeiro: Jorge Zahar.

Margulis, L. (2013). The symbiotic planet: a new look at evolution [Kindle]. Retrieved from Amazon.com

Maturana, H. R., \& Varela, F. J. (1987). The tree of knowledge. Boston: Shambhala Publications.

Miller, G. (2005, July 01). What is the biological basis of consciousness? Science, 309(5731), 79. doi: 10.1126/science.309.5731.79

Moreira, M. A. (2009, Abril). O modelo padrão da física de partículas [online]. Revista Brasileira de Ensino de Física, 31 (1), 1306-1311.

Recuperado em 26 de abril de 2016, de http://www.scielo.br/scielo.php?script=sci_arttext\&pid=S1806$11172009000100006 \&$ lng $=$ en\&nrm $=$ iso\&tlng $=$ pt

Musser, G. (2010). Could time end? Scientific American, 303(3), 84-91.

Nicolelis, M. A. L. (201 1). Mind out of body. Scientific American, 304(2), 8083.

Novello, M. (2012). O bóson de Higgs e a massa de todos os corpos. Scientific American Brasil, 124, 42-49.

Orgel, L. E. (2004). Prebiotic chemistry and the origin of the RNA world. Critical Reviews in Biochemistry and Molecular Biology [online], 39(2), 99123. doi: 10.1080/10409230490460765. Recuperado em 26 de abril de 2016, de http://bonhamchemistry.com/wpcontent/uploads/2012/01/RNA_World.pdf

Pennisi, E. (2005, July 01). Why do humans have so few genes? Science, 309(5731), 80. doi: 10.1126/science.309.5731.80

Pennisi, E. (2009, November 06). No genome left behind. Science, 326(5954), 794-795. doi: 10.1126/science.326_794

Pennisi, E. (2010, May 21). Genomics. Synthetic genome brings new life to bacterium. Science, 328(5981), 958-959. doi:

$10.1126 /$ science.328.5981.958

Prusiner, S. B. (1984). Prions. Scientific American, 251 (4), 50-59.

Pigliucci, M. (2009, February 06). The overwhelming evidence, Science, 323(5915), 716-717. doi: 10.1126/science. 1168718

Reale, G., \& Antiseri, D. (2003). Filosofia pagã antiga. In História da filosofia (Vol. 1). São Paulo: Paulus. 
Riess, A. G., \& Turner, M. S. (2004). From slowdown to speedup. Scientific American, 290(2), 62-67.

Riordan, M., Tonelli, G. \& Wu S. L. (2013, May 21). The Higgs at last. Scientific American, 307(4), 66-73.

Schmidt, K. (2000). Gobekli Tepe, Southeastern Turkey: a preliminary report on the 1995-1999 excavations. Paléorient [online], 26(1), 45-54.

Recuperado em 26 de abril de 2016, de http://www.persee.fr/doc/paleo_0153-9345_2000_num_26_1_4697

Seife, C. (2005, July 01). Can the laws of physics be unified? Science, 309(5731):82. doi: 10.1126/science.309.5731.82

Smolin, L. (2004). Atoms of space and time. Scientific American, 290(1), 6675.

Steiner, J. E. (2006). A origem do universo. Estudos Avançados [online], 20(58),231-248. Recuperado em 26 abril de 2016, de http://www.scielo.br/scielo.php?pid=s0103$40142006000300022 \&$ script $=$ sci_arttext

Tinôco, C. A. (1996). As Upanishads. São Paulo: IBRASA.

Tomasello, M. (2000). Primate cognition: Introduction to the issue. Cognitive Science, 24(3), 351-361. Recuperado em 25 de março de 2016, de http://onlinelibrary.wiley.com/store/10.1207/s15516709cog2403_1/asset /s15516709cog2403_1.pdf; ;sessionid =344ED0CDA2E6EEB55C9AF43C FD9185AD. $f 01+04 ? v=1 \& t=i m f 476 x f \& s=945 b 2 f 0 f 2 e a f 745 d 5064 d 9 a 373$ $3238 c 29 c c e 77 a 7$

Turner, M. S. (2009). Origin of the universe. Scientific American. 301 (3), $36-$ 43.

Veneziano, G. (2012). The myth of the beginning of time., Scientific American, 290(5), 54-65.

Vernadsky, V. I. (1998). The biosphere [Kindle]. New York: Copernicus/Spring-Verlag. Retrieved from Amazon.com

von Franz, M. (2003). Mitos de criação. São Paulo: Paulus.

Wilkins, C. (1785). The Bhagavad Gita, in the Public Domain [Kindle]. Retrieved from Amazon.com

Zilhão, J., Angelucci, D. E., Badal-García, E., d'Errico F., Daniel, F., Dayet L., ... Zapata, J. (2010). Symbolic use of marine shells and mineral pigments by Iberian Neanderthals. Proceedings of the National Academy os Sciences of the United States of America, 107(3), 1023-1028. doi:

10.1073/pnas.0914088107. Recuperado em 26 de abril de 2016, de http://www.pnas.org/content/107/3/1023.full

Zimmer, C. (2009, January 09). On the origin of life. Science, 323(591 1):198-199. doi: 10.1126/science.323.5911.198 
Zoja, L. (2005). Carl G. Jung como fenômeno histórico-cultural. Cadernos Junguianos, 1, 18-31.

Minicurrículo: Ricardo Pires de Souza - Analista junguiano, membro do Instituto Junguiano de São Paulo (IJUSP), Associação Junguiana do Brasil (AJB) e International Association for Analytical Psychology (IAAP). Doutor em Medicina pela Universidade de São Paulo (USP). Médico assistente do Departamento de Diagnóstico por Imagem da Escola Paulista de Medicina / Universidade Federal de São Paulo (Unifesp). Autor dos livros "Anima Mundi" (2004) e "A Dança de Shiva" (2010), poesia, pela Ateliê Editorial, São Paulo. E-mail: ricapires@uol.com.br 